\title{
Physical Modelling for Investigation of Cracking in Masonry Walls due to Thermal Movements of an Overlying Slab
}

\author{
K.G.S. Dilrukshi and W.P.S. Dias
}

\begin{abstract}
This paper describes the use of $1 / 3$ scale physical models to investigate the deformations generated and cracking in walls due to the thermal movements of an overlying slab. In this study three models were constructed to identify the effect of the structural form and aspect ratio of the wall on the formation + of cracks. Temperature variations in the models, strains generated and formation of cracks were observed. The effect of the structural form and aspect ratio of the walls on the above phenomena were identified. The results were compared with numerical and field survey studies.
\end{abstract}

\section{Introduction}

Concrete slabs exposed to direct sunlight experience temperature related horizontal movements. In addition, temperatures on the top surface will be higher than those on the underside of the slab, causing an upward movement of the slab during heating. In a typical building, masonry and concrete structural elements are connected to each other at their respective interfaces. Therefore, significant movements may be generated in the masonry walls due to the movement of the roof slab. These movements can result in overstressing and cracking in masonry. Even though such non structural cracking of masonry is not a normal structural design consideration, these cracks lead to considerable problems with respect to the performance and appearance of a building. Hence studying these cracks and factors causing them is important, in order to propose remedial measures.

Masonry structures represent one of the oldest forms of construction and different types of masonry components have evolved over the years both in this country and all over the world. Before the development of numerical tools and advanced computer techniques, the design of masonry structures has been in the main based on empirical rules supported by analytical and experimental observations. The main advantage of a physical model over an analytical model is that it portrays the behaviour of a complete structure loaded to a failure state. Also, physical models represent a better idealization of the actual structures than numerical models, especially with respect to the boundary conditions and the anisotropic nature of materials.

The prime motivation to conduct experiments on structures at a reduced scale is to reduce the cost and the difficulties in testing. The choice of the geometric scale factor for a specific type of model depends on a number of factors including the available loading system, fabrication facilities and adequacy of representation.

This paper describes an investigation that used $1 / 3$ scale physical models. In this study three models were constructed to identify the effect of structural form (using models representing 6 $\mathrm{m}$ long load bearing and concrete framed walls) and the effect of aspect ratio (using models representing $3 \mathrm{~m}$ long and $6 \mathrm{~m}$ long load bearing walls) on the above phenomenon. The movements generated on the model walls when the roof slab is subject to thermal loads due to direct sunlight were carefully monitored. The results were compared with corresponding numerical and field survey observations. The objective of the physical modelling was not to establish an equivalence between model and prototype. Rather the objective of the study was more limited, i.e. to investigate the movements developing and cracks forming on the masonry walls and to understand the relative importance of factors that cause cracking, such

K.G.S. Dilrukshi, BSC Eng (Hons), PhD is a Senior Lecturer in Civil Engineering at the University of Moratuzua.

Prof. W. P. S. Dias, PhD, MIStructE, FIE(Sri Lanka) is a Senior Professor of Civil Engineering al the University of Moratuzoa. 
as the structural form of wall (i.e. whether the wall is load bearing or within a concrete frame) and aspect ratio of wall, and also to validate the numerical model.

\section{Literature review}

The literature shows that, depending on the requirement, reduced size structural models have been customarily used in research studies and widely employed in research programs in such applications as:

1) Development of experimental data for verification of the proposed, analytical methods.

2) Study of basic behaviour of complex structural forms such as shells.

3) Parametric studies on member behaviour.

4) Behaviour of complex structural systems subject to complex loading histories.

Even though the methodology of using small scale modelling in structural research and design dates back many years, the techniques have improved considerably in the past few decades ciue to the improvements in instrumentation. The small scale modelling technique has been successfully applied to investigate problems in masonry and has proven to be a powerful technique that is an economical alternative to full scale testing.

The literature (Gajanan et al. 1983, Bechara et al. 1990) states that the first successful attempt to model masonry structures was made in England by Vogt in the mid 1950 s using $1 / 4$ scale bricks and later $1 / 10$ scale bricks. The subsequent work of Hendry, Murthi and Sinha at the Edinburgh University in the 1960s on brickwork using $1 / 3$ and $1 / 6$ scale models is considered as a successful development in masonry modelling. Later the technique has been developed and used by many researchers for their investigations.

Samarasinghe (1981) has used $1 / 6$ scale brick masonry specimens to investigate in-plane behaviour of masonry and developed bi-axial failure criteria for masonry. To study behaviour of unreinforced masonry under biaxial pseudo dynamic loading, Senthival and Uzoegbo (2004) have used $1 / 2$ scale models. Around 700 tests of large and small scale static and dynamic tests have been considered to evaluate lateral load resistance of masonry infill walls by Henderson et al. (2003). Hughes and Kitching (2000) have used $1 / 6$ and 1/12 scale models to determine the properties of a range of brickwork composed of different model mortars in a number of different geometric test configurations
Any given model built in a laboratory has an optimum geometric scale factor. Very small models require light loads but can present great difficulties in fabrication and instrumentation. Large models are easier to build but require much heavier loading equipment.

\section{Materials and methods}

\subsection{Choice of scale and models}

The review of literature has shown that models built to the reduced scale of $1 / 3$ to $1 / 6$ are considered as suitable for studying masonry structures. In this study, the scale factor of $1 / 3$ was selected to construct the models considering factors such as availability of materials, controlling workability and ease of monitoring.

Observations from the building survey and results of numerical modelling (Dilrukshi and Dias 2008; Dilrukshi 2008) indicate that the length of load bearing walls has a significant effect on the location and the orientation of these cracks. Therefore, to capture this effect, models were constructed to represent $3 \mathrm{~m}$ and 6 $m$ long load bearing walls. It was also understood that the structural form of the wall has a significant effect. To investigate this effect, a model which represented a $6 \mathrm{~m}$ long concrete framed wall was constructed in addition to the load bearing walls. The details of the models used in this investigation are shown in Table 1.

Table 1 - Description of physical models used in the study

\begin{tabular}{|c|c|c|c|}
\hline \multicolumn{2}{|c|}{ Entity } & $\begin{array}{c}\text { For } \\
\text { prototype }\end{array}$ & $\begin{array}{l}\text { For } \\
\text { model }\end{array}$ \\
\hline \multirow{3}{*}{$\begin{array}{l}\text { Length of } \\
\text { walls }\end{array}$} & $\begin{array}{l}\text { Model I } \\
\text { Load } \\
\text { Bearing }\end{array}$ & $3 \mathrm{~m}$ & $1 \mathrm{~m}$ \\
\hline & $\begin{array}{l}\text { Model II - } \\
\text { Load } \\
\text { Bearing }\end{array}$ & $6 \mathrm{~m}$ & $2 m$ \\
\hline & $\begin{array}{l}\text { Model III - } \\
\text { Concrete } \\
\text { Framed }\end{array}$ & $6 \mathrm{~m}$ & $2 \mathrm{~m}$ \\
\hline \multicolumn{2}{|c|}{ Height of walls } & $3 \mathrm{~m}$ & $1 \mathrm{~m}$ \\
\hline \multicolumn{2}{|c|}{ Size of colunus } & $0.3 \mathrm{~m} \times 0.3 \mathrm{~m}$ & $0.1 \mathrm{~m} \times 0.1 \mathrm{~m}$ \\
\hline \multicolumn{2}{|c|}{ Size of beams } & $0.3 \mathrm{~m} \times 0.5 \mathrm{~m}$ & $0.1 \mathrm{~m} \times 0.17$ \\
\hline \multicolumn{2}{|c|}{$\begin{array}{l}\text { Maximum aggregate size for } \\
\text { mortar and plaster }\end{array}$} & $4 \mathrm{~mm}$ & $1.4 \mathrm{~mm}$ \\
\hline \multicolumn{2}{|c|}{$\begin{array}{l}\text { Maximum agsregate size for } \\
\text { concrete }\end{array}$} & $20 \mathrm{~mm}$ & $10 \mathrm{~mm}$ \\
\hline
\end{tabular}


The models were simplified to represent the effect of the concrete slab on walls which are typically $3 \mathrm{~m}$ apart in plan. The area of slab which experiences an upward deflection has a direct influence to generate movements on the wall. Hence, for simplicity we were only concerned about this area of the slab, which was considered as approximately equal to a length of $\mathrm{L} / 4$ to each side from the centre of the wall (where $\mathrm{L}$ is the span of the slab between two supports). The details of this simplification are shown in Figure 1.
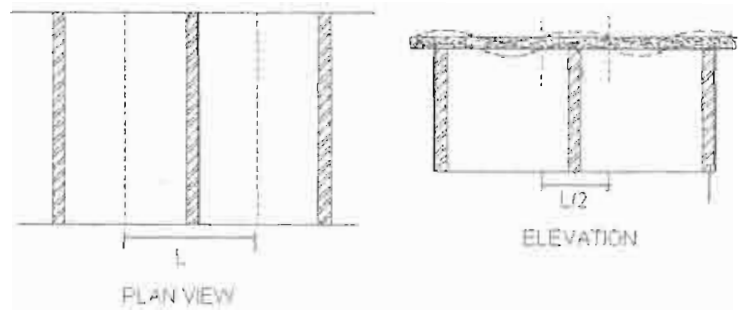

Figure 1-Simplification of the model

\subsection{Materials used and construction of models}

The bricks employed in this project were clay bricks normally available in the local market. Bricks were cut to the size of $75 \times 36 \times$ $24 \mathrm{~mm}$, i.e. $1 / 3$ scale of the standard size bricks. A diamond cutter was used to cut bricks according to the requirements. The aggregate passing through a $4 \mathrm{~mm}$ sieve is defined as the fine aggregate for normal (prototype) construction. In order to satisfy the $1 / 3$ ratio in the models, the maximum aggregate size was taken as approximately $1 / 3$ of $4 \mathrm{~mm}(1.33 \mathrm{~mm})$ and aggregate passing through the $1.4 \mathrm{~mm}$ sieve was used for the study.

A mortar mix of 1:6 (cement: sand) by volume was used for the construction of wall panels. This mortar mix is usually used by masons for construction of brick masonry walls in Sri Lanka. The water/cement ratio used for our mortar mix was around 1.2, which was just sufficient as judged by the brick layer. This is not much higher than that used for usual construction, in spite of the fine sand particles in the mortar used for the model.

A location that receives long hours of sunlight was selected for the construction of models. The intention was to obtain the maximum amount of thermal radiation from the sun. The ground was firmly levelied and precast concrete beams were placed on the ground as the foundations for the models. The soil at this location was hard laterite and hence the possibility of settlements was minimal. Moreover the loads from the models are very small, and we could assume that settlement would not be the cause of any cracking.

Two models of length $1 \mathrm{~m}$ and $2 \mathrm{~m}$ were constructed to represent load bearing walls of length $3 \mathrm{~m}$ and $6 \mathrm{~m}$ respectively. The $1 \mathrm{~m}$ height of both walls represented $3 \mathrm{~m}$. A $4 \mathrm{~mm}$ thick mortar joint representing around $10-12 \mathrm{~mm}$ in the prototype) was maintained between the brick units. Walls were constructed according to the standard English bond pattern. Bricks were immersed in water for about 10 minutes before the construction of wall panels. One of the major variables in brickwork construction is the standard of workmanship. In order to reduce the variability in workmanship, the same experienced brick layer was employed to build all the models. A $50 \mathrm{~mm}$ thick slab was constructed to represent the $150 \mathrm{~mm}$ slab of the prototype. The maximum size of coarse aggregate was limited to $10 \mathrm{~mm}$ in the concrete mix and $6 \mathrm{~mm}$ diameter mild steel was used as the reinforcement.

A concrete framed model with two columns of size $100 \times 100 \mathrm{~mm}$ at the edges and a beam of $100 \times 170 \mathrm{~mm}$ was constructed to represent a 6 $\mathrm{m}$ long wall in the prototype. Mild steel reinforcement of size $6 \mathrm{~mm}$ diameter was used for the construction of both beam and columns. The columns were constructed first and the masonry wall was constructed later as an infill wall. The methodology used for the construction of the load bearing wall models was used for the construction of the infill wall and roof slab.

A $5 \mathrm{~mm}$ thick plaster was used in all walls of the $1 / 3$ scale model to represent the $15 \mathrm{~mm}$ thick plaster of the prototype. A mortar mix of 1:5 (cement: sand) was used for the plastering, once again with a maximum aggregate size of $1.4 \mathrm{~mm}$.

Curing of masonry and concrete was done for a period of 28 days under damp hessian and the model walls were protected against direct solar radiation by covering them with plywood sheets, in order to ensure that solar radiation was experienced only by the slabs and not the walls. The long curing period was to make the materials as strong as possible, with correspondingly high $\mathrm{E}$ value, so that the generation of cracks duc to movements would be encouraged. 


\subsection{Loading}

The main load associated with this study is the thermal load on the slab due to direct solar radiation.

Modelling of the dead weight stresses is not easy in structural engineering studies using small scale models. In this study, special attention was not paid for modelling of dead weight because it was understood that lower dead weight would help to magnifying the upward movement and hence facilitate the study of the thermal phenomena.

3.4 Strain measurements using a mechanical strain gange

The movements of the walls were initially measured using a mechanical strain gauge. The results of a preliminary numerical model study (Dilrukshi 2008) were used to identify the locations and directions in which datum discs had to be fixed. A description of the selected locations and their directions for the installation of strain gauges is given in Table 2 and Figure 2 ( $l$ is the length of the wall). The datum discs were placed on both the East face (Face 1) and the West face (Face 2)

The distance between a pair of datum discs was kept at around $4 \mathrm{~cm}$. The measurements were taken once a wcek on a selected sunny day. To capture the diurnal variation of movements, readings were taken at 7.00 a.m., 10.30 a.m., 12.30 p.m., 3.00 p.m. and 6.00 p.m. on each selected day

Table 2 - Details of strain measuring locations

\begin{tabular}{|c|c|c|c|c|c|c|}
\hline \multirow{2}{*}{ Location } & \multicolumn{2}{|c|}{$\begin{array}{c}1 \mathrm{~m} \text { loadl bearing } \\
\text { model }\end{array}$} & \multicolumn{2}{c|}{$\begin{array}{c}2 \mathrm{~m} \text { load bearing } \\
\text { model }\end{array}$} & \multicolumn{2}{c|}{$\begin{array}{c}2 \mathrm{~m} \text { concrete framed } \\
\text { model }\end{array}$} \\
\cline { 2 - 6 } & $\begin{array}{c}\text { Distance } \\
\text { from the } \\
\text { outer } \\
\text { edge }\end{array}$ & $\begin{array}{c}\text { Orientation } \\
\text { to horizontal } \\
\text { (degrees) }\end{array}$ & $\begin{array}{c}\text { Distance } \\
\text { from the } \\
\text { outer } \\
\text { edge }\end{array}$ & $\begin{array}{c}\text { Orientation } \\
\text { to horizontal } \\
\text { (degrees) }\end{array}$ & $\begin{array}{c}\text { Distance } \\
\text { from the } \\
\text { outer } \\
\text { edge }\end{array}$ & $\begin{array}{c}\text { Orientation } \\
\text { to horizontal } \\
\text { (degrees) }\end{array}$ \\
\hline H & $0.5 l$ & 0 & $0.5 l$ & 90 & $0.5 l$ & 0 \\
\hline V & $0.5 l$ & 90 & $0.5 l$ & 0 & $0.5 l$ & 90 \\
\hline D1 & $0.25 l$ & 25 & $0.17 l$ & 25 & $0.08 l$ & 45 \\
\hline D2 & - & - & $0.2 l$ & 25 & $0.17 l$ & 45 \\
\hline D3 & $0.25 l$ & 25 & $0.17 l$ & 25 & $0.08 l$ & 45 \\
\hline D4 & - & - & $0.2 l$ & 25 & $0.17 l$ & 45 \\
\hline & & & & & & \\
\hline
\end{tabular}

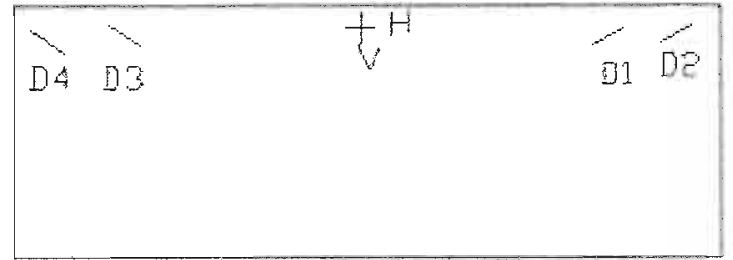

Figure 2 - Strain measuring locations

\subsection{Strain measurements using digital strain ganges}

Strain gauges of length $100 \mathrm{~mm}$ and 30 $\mathrm{mm}$ were used to measure strains of the concrete and the masonry respectively. Locations selected to install strain gauges are the same as above. The time interval for measurements was set to 10 minutes Measurements were started 6.30 a.m. and continued for a period of 36 hours.

The strain gauges are subject to expansions and contractions due to the temperature variations of the gauge itself. The strain values which are recorded by the data logger contain these temperature induced strains. Therefore to obtain actual values of the masonry strains we need to remove this temperature effect from the readings. The temperature of the strain gauges will be almost equal to the temperature of the masonry wall. The corrected reading $(\gamma)$ can be obtain as;

$\gamma_{\mathrm{r}}=\gamma_{r}-\left(t-t_{0}\right) k$

where;

$\gamma_{c}$-Corrected strain reading 
$y_{1}$-Strain reading obtained by data logger

$t$ - Temperature corresponding to reading

$t_{0}$ - Reference temperature (temperature at 6.30

a.m.)

$k$ - Temperature coefficient of gauge factor of the strain gauge $\left(+0.00011 .5 \% /{ }^{\circ} \mathrm{C}\right)$

\subsection{Temperature measurements}

Diurnal temperature variations of the top and the bottom surfaces of slabs, walls and. beam (in the framed wall) were measured simultaneously with the strains. A multi meter with surface probe was used for these measurements.

\section{Results and Discussion}

\subsection{Temperature variation}

The temperature variations observed on the 2 $\mathrm{m}$ load bearing and the $2 \mathrm{~m}$ concrete framed model walls within a period of 36 hours starting from 6.30 a.m. are shown in Figure 3 and Figure 4 respectively. The variations are cyclic in both models. At $6.30 \mathrm{a}$.m. in the morning, the temperature of the structures stood at around $23^{\circ} \mathrm{C}$. It increased gradually and reached a peak by 2 p.m. and then started to decrease. During the night the temperature was much lower. The maximum temperature gradient across the slab also occurred around 2 p.m. At the troughs, the temperature of the whole structure seems similar. This means that the models have achieved thermal equilibrium with the surrounding temperature. At peaks there is a gradient of temperature through the depth of slab, because of the solar radiation. Normally the upper surface of the slab should reach higher temperatures earlier than the cooler lower layers. Therefore the top surface of the slab reaches its peak before the bottom. This can be clearly observed at the second peak in both cases. The difference of the temperature from top surface of the slab to the wall is higher in the framed wall than the load bearing wall (Table 3). The greater concrete depth due to the presence of a beam is the reason for this difference. In general, the observations from the study show that the models have experienced a thermal gradient approximately equal to that estimated for the prototype.

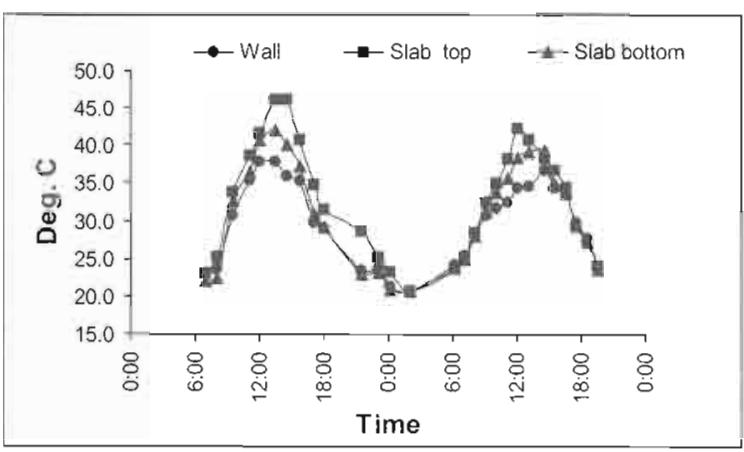

Figure 3 - Temperature variation of $2 \mathrm{~m}$. load bearing wall model

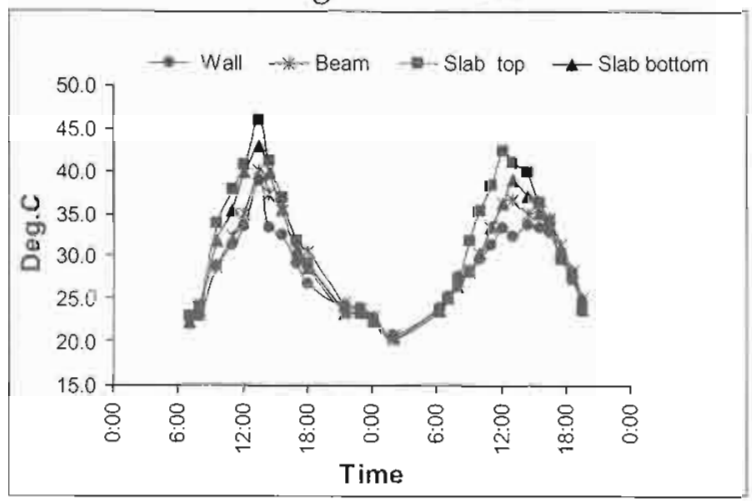

Figure 4 - Temperature variation of $2 \mathrm{~m}$ concrete framed wall model

Table 3 - Temperature values at top of the slab and the wall as the top surface reaches its peak

\begin{tabular}{|l|c|c|c|c|}
\hline \multirow{2}{*}{ Model } & \multicolumn{2}{|c|}{ Day 1 } & \multicolumn{2}{c|}{ Day 2 } \\
\cline { 2 - 5 } & $\begin{array}{c}\text { Slab } \\
\text { top } \\
\left({ }^{\circ} \mathrm{C}\right)\end{array}$ & $\begin{array}{c}\text { Wall } \\
\text { top } \\
\left({ }^{\circ} \mathrm{C}\right)\end{array}$ & $\begin{array}{c}\text { Slab } \\
\text { top } \\
\left({ }^{\circ} \mathrm{C}\right)\end{array}$ & $\begin{array}{c}\text { Wall } \\
\text { top } \\
\left({ }^{\circ} \mathrm{C}\right)\end{array}$ \\
\hline $\begin{array}{l}\text { Load bearing } \\
\text { wall }\end{array}$ & 46 & 37.7 & 42.2 & 34.4 \\
\hline $\begin{array}{l}\text { Concrete framed } \\
\text { wall }\end{array}$ & 46 & 36.8 & 42.3 & 32.2 \\
\hline
\end{tabular}

\subsection{Crack observations}

Around 1.5 months after the construction of models, cracks were noticed in the concrete framed wall (Figure 5, with crack lines enhanced for clarity). A crack had been formed horizontally under the beam (Figure 5(a)) and had become diagonal towards the column at the edge of the wall (Figures 5(c) and (d)). The inclinations of diagonal cracks were around $45^{\circ}$ to the horizontal. This is similar to the observations on the concrete framed walls in the building survey (Dilrukshi and Dias 2008). It is also similar to the principal stress directions identified in the numerical modelling for concrete framed walls. 
It was observed that cracks had formed immediately under the concrete beam (Figure $5(a)$ ) on one side of the wall (on both faces) while they had formed much lower on the other side (Figure 5(b)). The observations perhaps suggest the presence of a weaker area due to workmanship deficiencies on one side of the wall.

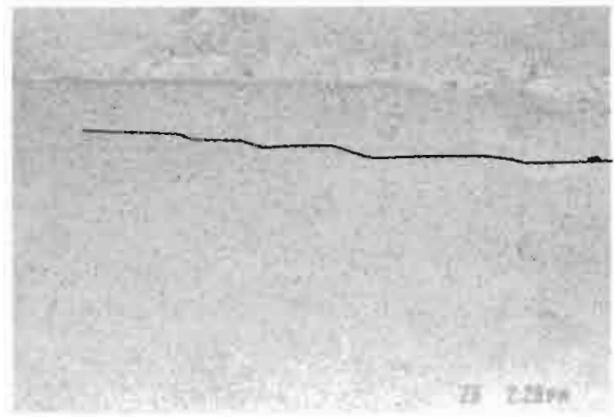

(a)

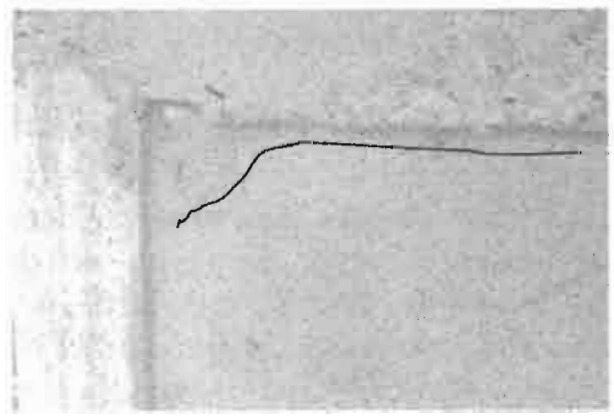

(c)

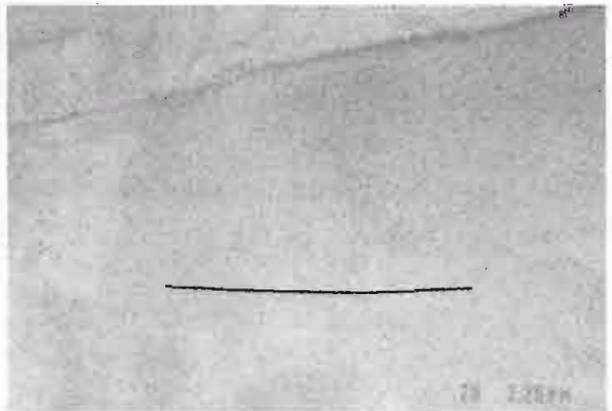

(b)

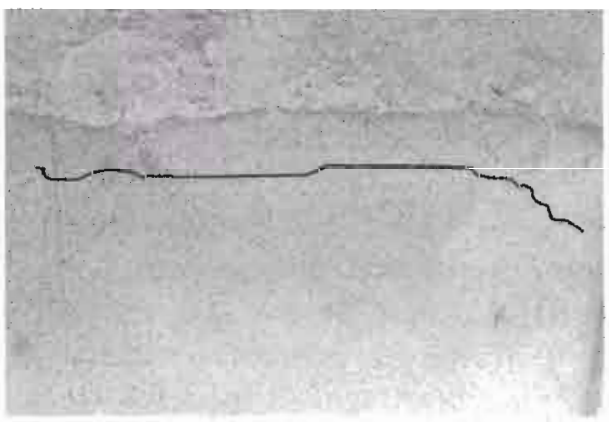

(d)

Figure 5 - Cracks in $2 \mathrm{~m}$ concrete frame model (around 1.5 months after the construction): (a) Horizontal crack immediately under the beam (the right hand side of the wall, West Face); (b) Horizontal crack below the beam level (the left hand side of wall, West Face); (c) Diagonal crack at the edge of the left hand side, East Face; (d) Diagonal crack at the edge of the right hand side, West Face.

The diagonal cracks have formed at the panel edge near the column on one end of the wall on both faces (Figure 5(c) and (d)). However, we can not see these diagonal cracks on the other end of the wall once again. Differences in workmanship below the beam level may be the cause for this variation.

Two years after construction, hair line cracks (inclination around $60^{\circ}$ to the horizontal) were seen on the $2 \mathrm{~m}$ load bearing wall model. Since the $1 \mathrm{~m}$ load bearing model wall collapsed accidentally during the attempted strain gauging operation, it could not be observed for an extended duration. However, it did not display any cracking in the 14 months under observation. The cracking observed on the $2 \mathrm{~m}$ load bearing wall and concrete framed wall models are compared in Figures 6 and 7 respectively. 


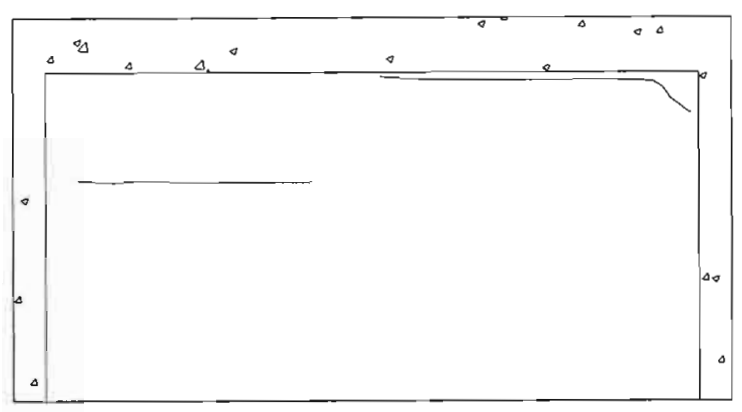

Figure 7 - Cracks in $2 \mathrm{~m}$ concrete framed wall model

4.3 Strain observations using mechanical strain gauge

Expansive strains in of walls during a single day were measured over a period of a year using a mechanical strain gauge. The readings were taken weekly. Since these expansive strains would be related to the overall temperature difference in the roof slab, expansions per degree of thermal gradient of roof slab were calculated. The average maximum daily expansions of walls observed are shown in Figures 8 to 10 .

In the $1 \mathrm{~m}$ load bearing wall model the maximum expansion has occurred in the horizontal direction $(\mathrm{H}>\mathrm{V}, \mathrm{D} 1$ and $\mathrm{D} 3$, see Figure 8 ), while the maximum expansion of the $2 \mathrm{~m}$ load bearing wall model is diagonal (D1, D2, D3 and D4 $>\mathrm{H}$ and $\mathrm{V}$, see Figure 9). This gives an indication about the effect of the aspect ratio of the wall on the movements of the load bearing walls. Since the results were obtained before the formation of cracks, this gives a clear picture about the elastic behaviour of the system.

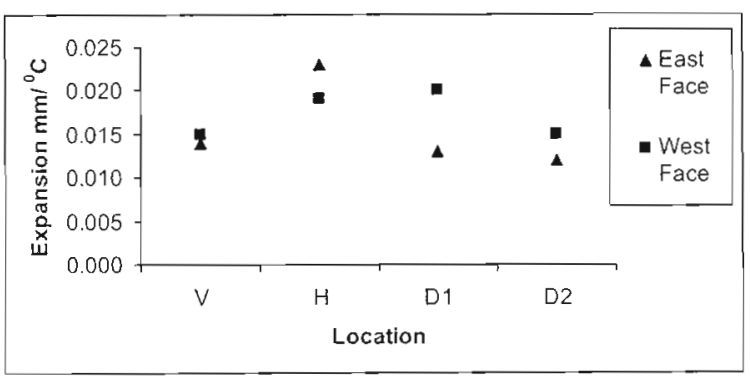

Figure 8 - Average maximum daily expansion of the $1 \mathrm{~m}$ load bearing wall (Model $\mathrm{I}$ )

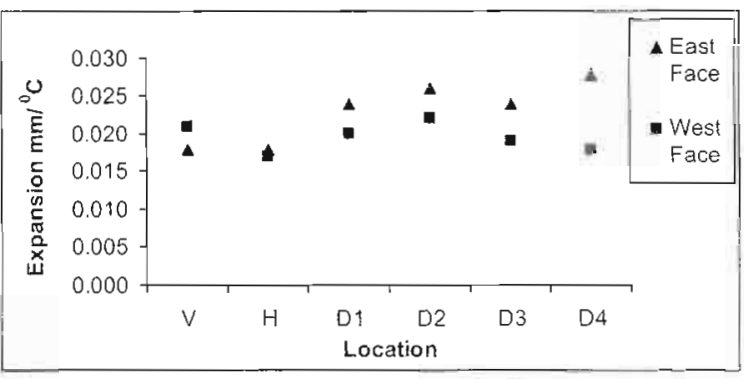

Figure 9 - Average maximum daily expansion of the $2 \mathrm{~m}$ load bearing wall model (Model

II)

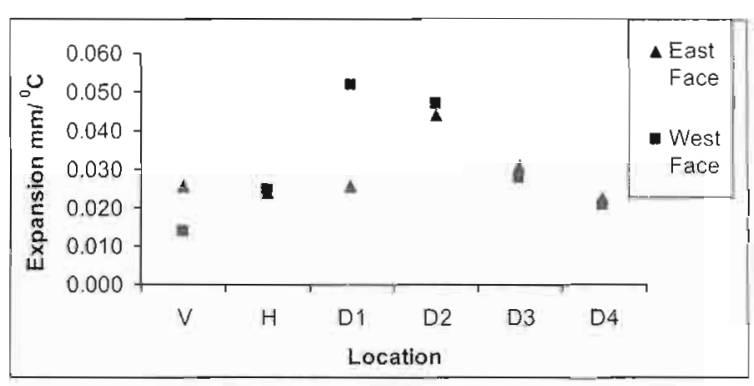

Figure 10 - Average maximum daily expansion of the $2 \mathrm{~m}$ concrete framed wall model (Model III)

In the concrete framed wall, the results were obtained after the formation of cracks (Figure $10)$. Since the stresses generated on the walls are released through formation of cracks, strain measurements do not give a clear picture about stress variations in the various directions. However the maximum stresses have been generated at the locations of cracks and their directions are perpendicular to the direction of cracks.

\subsection{Strain observations using digital strain gauges}

Later these movements were monitored using strain gauges and a data logger. Since these instruments are more sensitive than the mechanical strain gauge, the measurements are more accurate than the earlier ones. The strain observations are shown in Figures 11 and 12 These strains have the same pattern as the temperature variations of the roof slab (Figures 3 and 4). Hence it is clear that the cause for wall strains is the movements of the roof slab as a result of temperature variation in the slab.

The observations on the $2 \mathrm{~m}$ load bearing wall model in Figures 9 and 11 indicate that the maximum strain and hence the maximum movement of the wall has occurred in a diagonal direction at the edges while it is 
minimum in the vertical direction at the centre. A considerable amount of strain has been recorded in the horizontal direction at the centre too. Observations of movements using the mechanical strain gauge in the load bearing walls showed that when the aspect ratio of the wall is 1.0 the horizontal strain at the centre is higher than the diagonal strain at the edges (Figure 8).

Therefore there is a possibility of crack generation vertically close to the panel centre and downward inclined at the panel edge. Vertical cracking is more likely to occur when the wall is short and diagonal cracking when it is long. However, depending on the level of stress generated on the wall, the formation of both vertical and diagonal cracks are possible in long walls. The observations from the building survey also demonstrate this crack pattern on load bearing walls (Dilrukshi and Dias 2008).

In the concrete framed wall, cracks were present at the time of these strain measurements. The majority of planned strain gauging locations were across these cracks. These observations show that the methodology used to select the strain gauging locations is sound. The cracks that have deviated from the expected locations are probably due to material non homogeneity and workmanship deficiencies. The observations of strains at the uncracked locations of the framed wall are shown in Figure 12. The figure illustrates that all the strains have followed the pattern of diurnal temperature variations in the roof slab.

The crack pattern can be described as being horizontal under the beam at the centre and downward inclined at the panel edge near the column as regularly observed in concrete framed buildings during the building survey. Also, the results of the numerical simulations confirm this (Dilrukshi and Dias 2008).

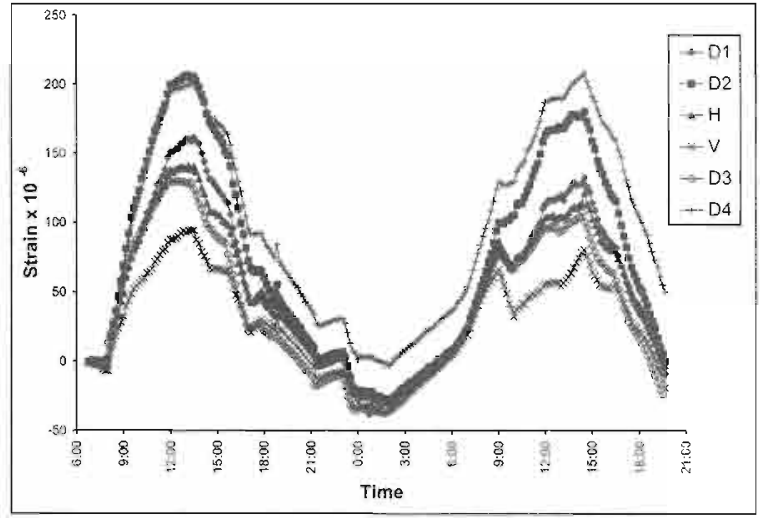

Figure 11 - Strain measurements in $2 \mathrm{~m}$ load bearing wall model - West Face

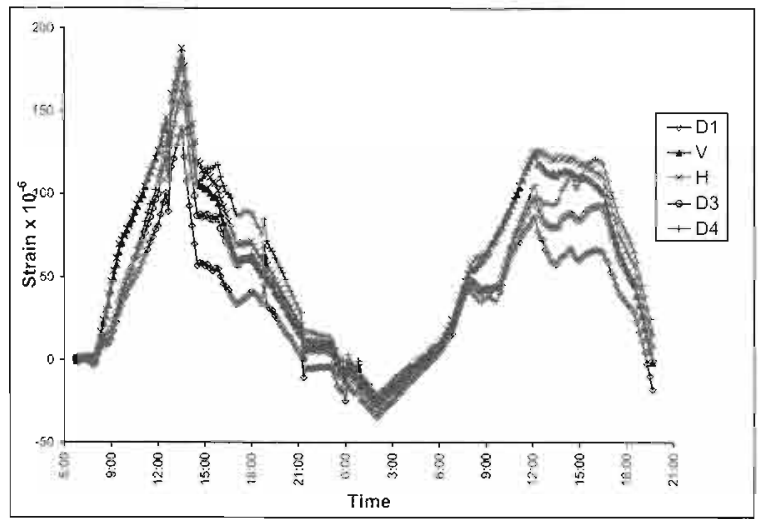

Figure 12 - Strain measurements in $2 \mathrm{~m}$ concrete framed wall model - East Face

\subsection{Quantitative validation of SAP2000 model}

The quantitative validation of the SAP2000 model was done by comparing the strain values produced by the model with the strain observations of the physical models. For this purpose the $1 / 3$ scale physical model that represented the $6 \mathrm{~m}$ load bearing wall was numerically simulated (including the temperature loading according to the physical model observations). The average strain observations of the physical model (at the selected locations described in Table 2) and the strain values obtained by the numerical simulation are shown in Table 4.

Table 4: Comparison of strains of $1 / 3$ scale load bearing model

\begin{tabular}{|c|c|c|c|c|}
\hline \multirow{2}{*}{ Location } & \multicolumn{2}{|c|}{$\begin{array}{c}\text { Average strain } \\
\text { scale load bearing } \\
\text { model }\end{array}$} & \multicolumn{2}{|c|}{$\begin{array}{c}\text { Strain obtained by } \\
\text { the numerical } \\
\text { simulation }\end{array}$} \\
\cline { 2 - 5 } & $\begin{array}{c}\text { Strain } x \\
10^{-6}\end{array}$ & $\begin{array}{c}\text { Direction } \\
\text { to } \\
\text { Horizontal }\end{array}$ & $\begin{array}{c}\text { Strain } x \\
10^{-6}\end{array}$ & $\begin{array}{c}\text { Direction } \\
\text { to } \\
\text { Horizontal }\end{array}$ \\
\hline D1 \& D3 & 170 & $25^{0}$ & 180 & $25^{\circ}$ \\
\hline D2 \& D4 & 195 & $25^{\circ}$ & 153 & $25^{\circ}$ \\
\hline H & 154 & $0^{0}$ & 144 & $0^{0}$ \\
\hline
\end{tabular}




\begin{tabular}{|c|c|c|c|c|}
\hline $\mathrm{V}$ & 101 & $90^{\circ}$ & 58 & $90^{\prime \prime}$ \\
\hline
\end{tabular}

The above results show that the strain observations of the physical model and the results of numerical simulation have reasonable agreement with each other, except at the location $\mathrm{V}$. Therefore the numerical model developed using SAP2000 can be considered as being reasonably well validated.

\subsection{Comparison of results with survey observations and numerical predictions}

In this study, small scale physical models were used to identify the effect of roof slab movements on solid walls. The main features associated with solid walls are the structural form and the aspect ratio of the wall.

According to the observations from the building survey (Dilrukshi 2008), cracks in load bearing walls can be identified as being vertical near the centre and inclined downward close to the ends of the wall. The inclinations of these diagonal cracks were around $50^{\circ}-60^{\circ}$ to the horizontal.

The observations of the physical models which represent load bearing walls have also confirmed this crack pattern. In the physical model wall which represented a short wall, the maximum strains were observed in the horizontal direction at the wall centre. In the wall which represented a long wall the strains measured in a diagonal direction close to the panel edge at 250 to the horizontal are the highest. The strains in the horizontal direction at the centre of this wall also displayed considerably high values. This implies that cracking in long load bearing walls is possible vertically at the centre and diagonally at the panel edges, as observed in the building survey.

The numerical modelling has aiso predicted the same phenomena (Dilrukshi and Dias 2008, Dilrukshi 2008). The results indicate that the maximum principal stresses in the short load bearing walls is at the wall centre in the horizontal direction and that it is at $25^{\circ}$ to the horizontal close to the panel edges in the long load bearing wall.

Horizontal cracking under the beam and diagonal cracking close to the column near panel edges were the most common types of cracks observed in the concrete framed walls during the building survey (Dilrukshi and Dias 2008, Dilrukshi 2008). The direction of the diagonal cracking was around $45^{\circ}$ to the horizontal. The cracks observed in the physical model which represented a concrete framed wall were also the same as the above. The strains observed in the vertical direction at the wall centre and diagonal directions (at $45^{\circ}$ to the horizontal) at the panel edges are the highest in this wall. The numerical models (Dilrukshi 2008) have also predicted diagonal cracking close to the wall edges (due to higher principal stresses in wall) and horizontal cracking under the beam (due to higher principal stresses in wall or higher tensile and shear stresses in the interface link elements).

\section{Conclusion}

1. Both the building survey and physical model observations demonstrate that the movements generated on walls due to the temperature of the roof slab follow the pattern of those diurnal temperature variations.

2. The pattern (type and location) of cracking depends significantly on whether the wall is load bearing or framed by the reinforced concrete elements.

3. Formation of horizontal cracks under the beams is common in concrete framed walls. They can be formed in the wall just under the concrete beam or at the masonry - concrete beam interface, usually at the weaker of the two.

4. Both types of structural arrangements give diagonal cracking near the ends of the walls, with the crack orientation steeper in load bearing walls. The diagonal cracks in concrete framed walls usually have inclinations of around $45^{\circ}$ to the horizontal and in load bearing walls it is generally around $60^{\circ}$.

5. Both the building survey observations and the strain observations in physical models show that in addition to the diagonal cracking at the edges, vertical cracking close to the centre is also possible in load bearing walls. When the wall aspect ratio is close to one 
(short walls) such vertical cracking is more likely than diagonal cracking at the edges. In long walls the formation of diagonal cracks at the ends is more likely, but both types of cracks could form.

\section{References}

1. Bechara E.A., Ahamad A.H. \& Harry G.H. (1990). Small scale modelling of concrete block masonry structures. ACI Structural Joumnl, Volume 87, pp 145-155.

2. Dilrukshi K.G.S., Dias W.P.S. (2008). Field survey and numerical modelling of cracking in masonry walls due to thermal movements of an overlying slab. Joumal of National Science Foundation Sri Lanka Volume 36(.3), pp 205-213

3. Dilrukshi K.G.S. (2008). Numerical and physical modelling of cracks in masonry walls due to thermal movements of an overlying slab, PhD Thesis, University of Moratuwa, Sri Lanka, 2008

4. Gajanan M.S., Harry G.H., Richard N.W. \& Mirza M.S. (1983). Structural modelling and experimental techniques. Prentice hall, Inc., Englewood Cliffs, USA.

5. Henderson R.C., Fricke K.E., Jones W.D., Beavers J.E. \& Bennett R.M. (2003). Summery of a large and small scale unreinforced masonry infill test program. ASCE Joumal of Structural Engineering, Volume 129, pp 1667-1675.

6. Hughes T.G. and Kitching N. (2000). Small scale testing of masonry. $12^{\text {th }} I B M a C$, Madrid, Spain.

7. Samarasinghe $W$. (1980). The in-plane failure of brickwork. PhD thesis, University of Edinburgh, UK.

8. Senthivel R. \& Uzoegbo H.C. (2004). Failure criterion of reinforced masonry under biaxial pseudo dynamic loading. Joumal of South African Institution of Civil Engineering, Volume 46, pp 20-24. 